\title{
Lessons from Lithuania: A pedagogical approach in teaching improvisation
}

\author{
Debra Hedden \\ University of Kansas, USA
}

\begin{abstract}
The purpose of this study was to uncover the approach that a professor in Lithuania utilized in successfully teaching undergraduate music education majors how to improvise during a onesemester course. The research questions focused on the participant's philosophy of teaching and learning, his methods for motivating students, the learning experiences he provided, and pedagogy that provided sequence of instruction and learning activities for the students. The research design consisted of a qualitative case study approach in which I interviewed the participant formally (three lengthy interviews), informally (seven casual conversations), and made six 90-minute observations of his improvisation classes. Inductive data analysis was employed to identify emergent themes. Those themes included (a) the freedom to create, (b) the act of convincing the students to engage, (c) the establishment of expectations, (d) the pedagogy and sequence of instruction that precipitated skill acquisition, and (e) the classroom environment that enhanced improvisational outcomes. The implications for teacher education are discussed.
\end{abstract}

Keywords: Improvisation, learning sequence, pedagogy, undergraduate music education

Corresponding author:

Debra Hedden, University of Kansas, 1530 Naismith Drive, Lawrence, KS 66047, USA.

Email: dhedden@ku.edu 
The music education literature in the last few years has contained a number of articles and research reports that focus on improvisation, defined by some as the art of creating music that occurs in the moment without written symbol. As Covington (1997) observed, "[i]mprovisation is important because it is able to fuse the three primary musical activities of composition, performance, and critical listening/analysis; it involves all three simultaneously" (p. 49). More specifically, Kratus (1995) defined improvisation as comprised of "purposeful, non-random movements to create musical sounds over time" that were the result of freely chosen pitches and rhythms and existed as a one-time event (p. 27). Burnard (2011) described both the art and process of improvisation as well as the process of teaching improvisation in the classroom as "flexible, adaptive, responsive, and generative activity" (p. 58).

For musicians, the acquisition of the art and skills of improvisation would appear essential to enhancing understanding of musical elements, improving performance, and creating music (rather than focusing on dependence on notation). If these skills were deemed important, then it would be prudent for music majors to receive concerted improvisation instruction in their degree programs. However, Shuler (1995) asserted that many music departments did not require faculty to teach improvisation to all students, and because of the cycle of training, most faculty members lacked experience in teaching improvisation. Five years later, Abrahams (2000) made a similar assessment, noting that faculty were deficient in improvisation training, resulting in limited offerings in improvisation for all students, and in these generally being reserved only for jazz students. Thus, it seems the lack of training appears to have perpetuated a cycle of preparing most musicians for the profession without integrating concerted improvisation training.

If we believe learning improvisation skills is necessary, how do we prepare musicians to teach them? Some studies suggested particular approaches for instruction. For example, Gamso (2011) described meshed instruction in which jazz methods were integrated into classical practice and into woodwind methods for collegiate students, arguing for more emphasis on focused listening. Covington (1997) recommended that "[o]ne area in which improvisation could be incorporated into the music curriculum and which would reach all music majors [was] aural training. Improvisation in aural pedagogy should not be just a discretionary choice but an essential component" (p. 49). The investigations with teaching, particularly those in music education degrees, highlighted the need for further study. The current study focused on the specific teaching of improvisation to music education majors during their preparation for teaching.

In the general context of teaching improvisation, Berliner (1987) described expert teachers' utilization of routines and organized learning experiences, infused with creativity, originality, and spontaneity. These descriptions suggested the use of constructivist approaches in teaching were supported by research and demonstrated positive results (see studies by Sawyer), but were most effective when infused with scaffolding strategies to enhance learning (Sawyer, 2011). Another approach in teaching was the apprenticeship model in which students learned through observation, participation, and practice, gaining skills and acquiring knowledge throughout the experience (Griffiths \& Woolf, 2009). These teaching pedagogies depended on some elements of teaching in the moment, using students' ideas that might suddenly shift the learning focus or outcome. 
Louth (2012) argued in favor of a pedagogy based on what he called "negative dialectics". This approach was an attempt to "balance[e] discipline and freedom" (Louth, 2012, p. 10) with results suggesting that both "subjective (freedom-oriented) and objective (discipline-oriented) aspects of improvisation be meshed" (p. 19). A pedagogical model for "improvisational intelligence" was conceptualized by Monk (2012, p. 90) which contained five cognitive skills: (a) the performance brain, or the physical element; (b) the creative brain, utilized for forming ideas; (c) the continuation brain where ideas were further explored; (d) the structural brain that organized; and (e) the temporal brain that decided direction of movement (p. 93).

More specifically, the literature of teaching improvisation has typically focused on jazz improvisation with college students (Bowman, 1988; May, 2003; Smith, 2009; Watson, 2010; Wehr-Flowers, 2006); however, the current study concentrated on non-jazz improvisation. Two such investigations originated in Europe. Wright and Kanellopoulos (2010) examined the learning journals kept by 91 preservice teachers who experienced an improvisation module. They noted that "improvisation might offer a route for creating an intimate, powerful, evolving dialogue between students' identities as learners, their attitudes towards children and their creative potential, and the interrelationships of the notions of expressive technique and culture ..." (Wright \& Kanellopoulos, 2010, p. 71). Furthermore, they discussed the value of the learning process in terms of the students' autonomy, as well as the ability to learn context and implicit knowledge.

Investigations in the United States of "non-jazz" improvisation with college students have used small-sample, qualitative methods. Della Pietra and Campbell (1995), for example, used ethnographic approaches with two students who took part in a five-week improvisation training segment presented as part of a music methods course. The authors noted that the two students became more sensitive to improvisation as a result of the experience. Seddon and Biasutti (2010) studied three college-age students as they used an e-learning environment to learn to improvise blues on the keyboard. They reported that the participants used five distinct learning strategies that included "instruction, copying, practicing, playing, and evaluating" (Seddon \& Biasutti, 2010 , p. 161), suggesting that the process was multidimensional and heavily reliant on musical memory.

Huovinen, Tenkanen and Kuusinen (2010) presented arguments about the number of marketed teaching methods, yet the absence of research to validate those approaches. Thus, they compared a music-theoretical approach, based on the elements of "scales, chords, and rhythm" (p. 83) with a "dramaturgical" one that focused on "freer forms ... that emphasize[d] [musical] expression and personal commitment" (p. 83) with students in a music pedagogy course. They concluded that each approach led to significant changes in the improvisations related to rhythmic and motivic variety, dissonance, and independence of chords against melodies. For the musictheoretical participants, the changes included more dissonance and less relation to particular chords, and for those using the dramaturgical approach, a greater variety in rhythm.

Because improvisation requires learners to take risks, the psychological element was important to teaching. For instance, in 2006, Wehr-Flowers investigated the variables of confidence, anxiety, and attitude among males and females learning jazz from middle-school to collegiate 
levels, and identified significant differences on all variables for females. Alexander (2012) conducted a study of 121 middle-school and high-school string players who participated in an improvisation curriculum over four months. He also utilized measures of confidence, anxiety, and attitude, and reported the only significant difference between them was anxiety, with the females being more anxious. According to Riveire (2006), removing fear from the experience fostered the ability to allow the mind to work without inhibitors.

The studies reported above certainly contribute to the literature about improvisation in general, but do not necessarily present a complete picture of how improvisation was taught or what was included in the teachings. While most of the evidence focused on general approaches or particular elements, the specific approaches to and sequence of instruction were virtually absent. Thus, there is scant evidence of research in the particular decisions a teacher makes regarding how improvisation is taught. The purpose of this study was to uncover the approach that a professor utilized in teaching students how to improvise during a one-semester course and thus contribute a model of a teaching approach to the profession. The research questions supporting this study were: (a) What philosophical underpinnings propelled the professor in terms of planning and delivering instruction to the students? (b) How did the professor motivate and engage students to learn the skill of improvisation, one for which they have not had previous preparation? (c) What kinds of learning experiences did the professor provide in teaching students to improvise? And (d) what particular pedagogies did the professor utilize in teaching improvisation?

\section{Method}

Because I am a professor of music education at a large university, my goal was to contribute to the professional preparation of teachers with an emphasis on praxialism. Lithuania was my home for a semester while I taught and undertook studies at the university where the participant was. I conducted this study with the greatest effort to remain open and unbiased, yet propelled by the lack of training I have witnessed in a variety of undergraduate programs.

This study, based on a post-positivist approach, asserts that the real-world context is essential to understanding the interactions of the people involved and results of those interactions. Patton (1990) stated that people's interactions are understood through common ground. Thus, the value of improvisation itself, the ability to converse and observe improvisational teaching in action, and the direct discourse involved with the participant were essential to this study. A naturalistic case study design appeared to be most appropriate, centered on a heuristic perspective to investigate the phenomenon of teaching students to improvise. This study embraced the descriptive aspect, focusing on "a process ... [and] lived experience" (Merriam, 2001, p. 4), typically inductive in nature, and as a bounded system that focused on the professor and his teaching (Smith, 1978).

\section{Access to the participant}

Purposeful sampling (Patton, 1990) allows the researcher to choose participants "because they can purposefully inform an understanding of the research problem and central phenomenon in 
the study" (Creswell, 2009, p. 125). Thus, it was imperative for me to conduct the study with a participant who exhibited excellence in teaching, impressive results with students, and a willingness to contribute to the body of research for the good of the profession. Furthermore, the participant facilitated the investigation of "discover[y], understand[ing], and gain[ing] insight" (Merriam, 2001, p. 61) as an "information-rich case" (Patton, 1990). From a previous visit to Lithuania, I had identified a participant, Lukas (a pseudonym), and acquired his permission to participate in the study.

\section{Procedures}

Rubin and Rubin (2005) argued that "responsive interviewing is what we have termed our approach to depth in interviewing research ... that the interviewer and interviewee ... form a relationship during the interview" (p. 30, original emphasis). That relationship was integral to acquiring accurate and comprehensive data to validate the study and it developed through both professional experiences at the university as well as personal encounters in social settings. During the course of a semester, I conducted three intensive, semi-structured interviews with Lukas, at approximately one-month intervals and of 65 to 80 minutes in length. The interviews consisted of a list of questions that I posed to allow Lukas to explain his approach to teaching improvisation, his background and training, and his specific pedagogy in the classroom (see Figure 1). During the course of each interview, his responses prompted a variety of additional questions that fueled further explication.

1. Please tell me how you learned to improvise and what training prepared you for teaching improvisation at the university level.

2. Describe your philosophy regarding the teaching of improvisation and the outcomes you believe are intended.

3. Do you believe it is important for students to learn to improvise? If so, why? If not, why not?

4. Describe the specific sequence of instruction you employ in teaching improvisation.

5. From where did your pedagogy of teaching come?

6. How do you begin improvisation instruction with the students?

7. What kinds of improvisation do you teach and what musical media are involved?

8. How do you motivate all students to participate in improvisational activities?

9. What kinds of experiences engage the students in improvisation?

10. How often does class meet and for what duration?

11. What learning experiences are integral to students learning the skills of improvisation?

12. How do you teach improvisation to music education majors in terms of strategies for learning?

13. Since I am new to this idea, please tell me more about the process of teaching and learning improvisation.

Figure 1. Initial interview questions for first interview.

"[I]deally, the qualitative research draws on some combination of techniques to collect research data, rather than a single technique" (Glesne \& Peshkin, 1992, p. 24). There were seven instances of informal conversations with Lukas that occurred during that time, casually taking place in the music office at the university, some of which were 30 minutes long. In those conversations I posed clarifying questions regarding previous data from the interviews. I also observed six of his 90-minute classes to substantiate data from the interviews and conversations; observing the teaching context was instructive in that it validated various elements that arose through the course of the interviews and conversations. An interpreter assisted me in the formal interviews 
and in the classes, all of which were in Lithuanian and were video- and audio-recorded. I composed field notes as well as recording his translations as we observed the classes. Later, there were verbal summaries reviewed by the participant through translation by an interpreter. He agreed that the data and interpretations were correct. In the informal conversations, Lukas and I spoke in German, a language common to both of us. The latter were not recorded, but I made field notes during each conversation. That I spent a lot of time interviewing and observing Lukas, then reformulating questions to further explicate certain data was important to the study. The time in the field was necessary to create a more complete picture of the decisions he made, the teaching sequence he chose, and the specific activities he undertook in the classroom.

Reliability was established through the multiple forms of data gathered, validity through member checks with the participant, and reaffirmation of accuracy by the interpreter and the participant. Triangulation (Stake, 1995) consisted of the congruence of data with the review of literature. Data analysis involved collecting open-ended data, based on asking general questions, from which an analysis developed (Creswell, 2009, p. 184) and on created transcripts of the observations. Befitting to this type of research, I used inductive data analysis to "build [their] patterns, categories, and themes from the bottom up, by organizing the data into increasingly more abstract units of information" (Creswell, 2009, p. 175). Thus, the patterns, categories, and themes emerged from which to report the findings and their interpretations.

\section{The findings}

From the data, five particular themes emerged that create the story of Lukas and his successes in teaching. The following presents his background and the themes, all of which meshed categories and patterns to substantiate the themes.

\section{Background information}

From the time he was around four years old, Lukas began improvising on the piano. It did not matter what color the keys were; he experimented across the keyboard. His description of sounds was akin to colors, drawing a parallel with painters as they used their imaginations to paint canvases. At the age of six or seven he began to improvise jazz, basing his improvisations on "imagination, sound descriptions, and images in my head". As he grew into his teenage years, he became more interested in American jazz, but was also influenced by European jazz. Information from books and recordings became a primary source of learning for him.

Musical standards were very high in Lithuania and his formal training was among the very best. "But at that time there were no courses for improvisation". Once Lithuania gained its independence in 1990, he noticed that schools were requiring public school music teachers to be proficient in improvisation, yet very few courses were available. During the past eight years he has taught improvisation at a pedagogical university in Lithuania and offered the required, semester-long course each fall for all undergraduate music education majors.

\section{Theme one: Freedom to create}


Lukas repeatedly mentioned that two primary goals existed that would facilitate both participation and success for the students. The first goal emphasized "freedom for student experimentation with improvisation" and if that freedom were perceived, the student would enjoy him/herself. In describing the process of learning as an exercise in freedom, he noted that "the whole goal of the exercise was not to put the student in some sort of frame, not to make them do something according to a preset frame[work]". Rather, it was to give students the opportunity to express themselves however they chose. Additionally, he emphasized that improvisation allowed all students to feel equal because each one created his/her own music. The second goal centered on the students' success leading to the acquisition of skill in preparation for teaching children how to improvise in their classrooms. Lukas underscored that improvisation was a form of creation, and in order to accomplish a creative act, the students had to experience the freedom in which to create. Creative experiences were the means of developing improvisational skills and of acquiring sufficient skills to use in their future classrooms. That improvisation would be used in their classrooms was important to Lukas because he argued that it would assist in "expanding children's learning ... and provide motivation and interest in learning beyond the typical lesson in singing or playing [an] instrument".

He explained that typical school classroom music classes were based "solely on singing, usually engaging only those who liked to sing"; but using improvisation could sharpen the musical skills of all students and provide ownership of the musical product, thus offering powerful learning to the students. Lukas adamantly argued that in schools children do what they are told to do, but "improvisation allow[ed] them to make musical decisions for themselves", contributing to deeper learning and enjoyment. Ultimately, he felt that improvisation would assist children in learning to love music, allowing them the freedom to create, and facilitating their comfort with it. Furthermore, he believed improvisation to be a convenient element of teaching because it served "to expand all other music learning" and children "would improve themselves".

\section{Theme two: Convincing the students}

Improvisation courses were compulsory for the students in the university music program, with nearly all music majors preparing for teaching. Although improvisation was required, there were many students who did not appear interested or motivated to learn. In his words, he described the situation:

So the main problem of this is definitely the fear of others, of audience, and definitely the reason why they are afraid the first time they do this. So the main task of the lecturer is to make them feel comfortable, to make like the environment comfortable, to make them feel okay, and to give them tasks that the students feel quite good and start [improvising].

He acknowledged that improvisation was difficult to learn and perceived as a frightening experience for most students because it occurred among peers who reacted as an audience.

Lukas' strategies for engaging students were concerted. He recognized that he first had to establish rapport with the students and make them feel comfortable. Some of his strategies appeared to be those that teachers and coaches would employ, for he talked with the students, 
shared stories of his life with them, and personally connected with them, establishing an environment that was safe. A primary goal was to make the students comfortable so that they would take risks in engaging in classroom improvisation activities. With all improvisation tasks, he was accepting, never criticizing. "I choose not to say 'no' to the students, but rather to redirect them", not prohibiting them.

Thus, he created an environment in which everything the students did was acceptable in order to facilitate their participation, their risk-taking, and their musical growth. His expectations were that all students in the class supported each other, in essence following his example of acceptance. He also relied on the element of aesthetics to help guide the students' work as well as their constructive comments of their classmates' work. In terms of motivating them, he insisted that "if we are here, let's not waste time; let's make something interesting for me and necessary for you [to learn]".

The realities of the classroom served as a motivator for the students, for he understood that school classrooms focused on singing, and that singular focus "limited the [acquisition of] musical skills". He asked his students what they would do when they began their teaching careers and had no equipment or instruments other than a piano in their classrooms.

\section{Theme three: Establishing expectations}

A goal of the improvisation exercises was not to put the students in a particular preset frame, but rather to allow for creativity and freedom of expression. Through the activities, he wanted the students to make musical decisions and expand their knowledge and skill; in contrast, he emphasized he did not want them to interpret these experiences as his attempt to create jazz musicians.

The students entered the course having had courses in theory and polyphony, so there was some knowledge of harmony when they began the class. Yet, he noticed that they had some preconceived notions of the way music "should sound". Lukas consistently reminded them that "there can be no mistakes in improvisation". So that he could put the students at ease and foster their creativity, he told the students that "when rules exist, they create the opportunity for mistakes". However, in his class, there were no rules and therefore, no mistakes. He encouraged participation, much of which embraced risk-taking. His particular approach to the class was focused on luring the students into the process, thus allowing them to experience success without having rules imposed. In his words,

... I try to get the students ... maybe ... to where I am wanting or expecting or hoping them to [improvise] but without trying to demonstrate anything as they should be doing.

Lukas used modeling to initiate activities; however, he encouraged and validated all students' attempts at improvisation to dispel fears and avoid inappropriate responses by their peers. The students were quite respectful of each other and frequently applauded as a student or group finished an improvisation exercise. 


\section{Theme four: Learning experiences}

Lukas began with basic elements of improvisation, those that would be easy and natural for the students, all without creating fear. To underscore the idea that everyone was equal and free to create, he said,

... first of all it is games. Every task is not based on very high theoretical aspects or tonation knowledge. First of all it's about games.

Games were the mechanism for the first improvisation exercises. Using the body, he began to clap a pattern and as the students stood in a circle, each one repeated his pattern before adding their own. Lukas then instructed someone in the middle to begin another pattern in a different meter to which the others would respond likewise, layering a variety of rhythmic patterns. Next, he asked a student to come to the piano, to identify her own pulse, then play that pulse on one key on the piano. As she did that, Lukas sat at the piano with her, playing music to that pulse. He cued her to play while he switched to the pulse. After several exchanges of piano playing, Lukas stopped to comment to the students that, from their position in the classroom, they could not determine who was playing music or pulse.

"Surrounding sounds" as he termed them, were very essential to improvisation, for they provided a familiar context in which to learn as well as sounds to imitate. Lukas asked each student to create a sound for icicles melting, then he expanded the exercise by having them create the "trees budding, flowers blooming, and snow melting". Next, he described a more sonorous activity:

And there are a lot of sounds in that village. One student will be wind, another hen and chicken, others like rain and so forth. It's like double improvisation. Teacher is like conductor. He asks students to play those sounds.

From this he introduced comical situations in which the students were intrigued. He set the stage by singing comically and saying,

For example, there is a spider who is living and some elephant falls down. And then I ask the student to continue. So definitely [a] very comic story is created. Definitely I am giving the tone and the instrument. Because it's really comic, the students really like those stories and they are waiting to the end, how it will end, with the spiders and the elephants.

The students were instructed to create sounds to complete the story, all of which were produced vocally. They laughed at the story and quickly engaged to create an ending that comprised the elephant getting bruised and beaten by the spider, finally limping away to avoid further confrontation.

Following successful learning experiences with comical situations, he smoothly transitioned to more personal expression by presenting a picture or verbally creating an image about which he asked "the students all the time to imagine something". The students would expressively respond through improvisation. He asked them to vocally or instrumentally communicate about that 
picture or image, forging greater expression that was both subtle and overt. In one instance, a blind student at the piano responded by using one repetitive note, all shaded with different dynamic levels and rhythms.

Several classes followed in which group improvisations occurred, all of which focused on familiar events and humorous situations. Lukas strategically delivered scenarios that motivated the students to participate. Once he felt the students had gained some comfort and were willing to continue with improvisations, he gradually moved into longer and more complex ideas. Subsequent improvisation activities encompassed more serious foci, such as a drama:

Even [a] more interesting thing is to ask students to create certain drama, for example, the car is crashing, something happens, like a movie with the soundtrack. Just the sounds.

His purpose was to create "a soundtrack without the movie". Because imagination played such a key role in this experience, he was able to segue to other experiences that facilitated more personal interpretations. For instance, he showed the class a picture or a short video, then asked them to create an interpretation as a group. At this point the students were using only their voices, body percussion, and a few sound sources in the classroom such as desks, benches, and notebooks for added elements, rather than instruments. Next, he said,

... I ask one group of students to go outside of the class, others to stay. So those who go outside of class, they decide together what they are going to play and then the rest should like guess what they are playing.

The group worked in the hallway, returning to present their improvisation about a rock concert; one student was the drummer, two more played air guitar, and one sang lyrics into an air microphone.

To segue to quasi-pitched vocal improvisation, Lukas arrived in class and began performing in rap style. The students were immediately transfixed and raised their hands to participate. He cued a student to join him, then another, eventually removing himself from the rap and allowing all of the students to participate. At this point, both unpitched percussion instruments and a trap set were presented to the class to use. The students quickly moved to these to add rhythmic accompaniment to the rap. Lukas cued the group to end the piece, which prompted everyone to clap.

In creating a segue between group improvisation and individual interpretations, he asked students if they had dreamed last night. He told a student to portray his dream. The student moved to the piano and sat down to play his interpretation that was then followed by another student who sang. Lukas deftly lured the students into using instruments and into presenting improvisations as solos. On another day Lukas began to play a piece on the piano in a minor key, establishing the meter and tone as dark and loud. Each student quickly exchanged places on the bench to play without losing a beat in the piece. When half of the students had played, Lukas quickly changed the key and meter for the remaining students to continue. 
Towards the end of the semester, the students jammed as a group on instruments in the classroom, changing them on cue from Lukas during a piece they created. They used an alto saxophone, two electric guitars, two trap sets, four recorders, and several unpitched percussion instruments. The students' comfort and their ability to adapt quickly to different instruments were noticeable. Lukas also gave groups of students an assignment during class to create a rock opera which they performed for each other. They had roughly 20 minutes to determine their story and develop the vocal parts before adding the accompaniment for performance. Or, using a tale they all knew such as Little Red Riding Hood, the students

... might then try to make it into a chamber opera on the spot. Somebody would play, somebody would sing, and somebody would act and they would do this exercise and it was actually be very helpful.

Lukas was adept in using text, images, and pictures to initiate improvisation in his class. He frequently reminded the students that they would likely "have only a piano and rhythm sticks in their music classrooms", so their charge was to create meaningful experiences for the children to enhance their creativity, participation, and musical skills. Furthermore, he explained that "the children would not have knowledge of keys or chords", so the teacher's responsibility was to provide learning experiences that would teach them skills to use by themselves or in a group.

\section{Theme five: The environment}

Lukas recognized that the setting for improvisation could greatly affect the students' motivation to participate and create fear due to change. Yet, he persuaded them to try a new venue, taking them into the formal concert hall and asking them to "sit on the stage with their instruments" (if they had them). Dancers from the dance degree program arrived and took places on the stage. While the dancers had prior knowledge that the musicians would be joining them, the improvisation students did not. Lukas began to improvise on the piano and the students gradually joined him with instrumental and vocal accompaniment for the dancers. "The students were so motivated by this experience that they decided to exchange [places] with the dancers". Thus, the dancers played instruments and sang while the improvisation students created movement. Lukas believed that while the formal setting of the concert hall might be intimidating initially, it also might allow for improved acoustics; second, since there were no rules imposed, everyone was free to make choices in their performance.

On other occasions, the improvisation students met on the stage in the concert hall, sitting in a circle. They would light some candles to imitate a friendly, intimate environment such as a campfire. Lukas encouraged the students to improvise, analyzing this situation as being very personal and akin to "a confession". He felt the freedom of creation and the intimacy of the setting allowed the students a venue that was more personal and individual in nature, yet one in which the students did not judge each other.

Overall, the particular skills Lukas used in establishing the environment, motivating students to participate and learn, and sequencing instruction served to demonstrate that the students became active participants in the experiences he provided. He commented that "the students become 
confident and acquire skills", for which many of them thanked him at the end of the course. He successfully convinced them of the necessity of acquiring these skills for their future classroom instruction. 


\section{Discussion}

\section{Philosophical underpinnings}

Lukas seemed to develop his philosophy over a period of years, beginning with his own experiences at a young age. He knew what was important for himself and appeared to use that as a guide in planning and implementing learning experiences for the students. Operating under the mantra of freedom to explore and create, he emphasized equality of musical genres, styles, and periods as well as among vocal, instrumental, and environmental media in the classroom, expanding his students' knowledge, skills, and independence. He consistently promoted the idea of the usefulness of learning improvisation not only to deepen his students' learning, but also to offer alternative ways to teach once they assumed teaching positions in schools.

\section{Motivation and expectations}

Lukas offered opportunities for the students to express themselves, emphasizing that there were no rules, thus no mistakes. In creating a comfortable environment and modeling ways to create musical products, he facilitated risk-taking and offered acceptance. The students learned through a variety of experiences, by observing his creations, and by witnessing their classmates' work (Griffiths \& Woolf, 2009). Ultimately, it appeared that the students' risk-taking provided for positive results, which might then fuel motivation to continue to experiment. Lukas was obvious in his efforts to make the experiences interesting to engage the students and facilitate growth of their skills (Covington, 1977) and created the environment and learning activities that would foster their success, implementing effective instructions, classroom parameters, and learning sequences for them to achieve success (Wright \& Kanellopoulos, 2010).

\section{Learning experiences}

The particular sequence of learning activities mirrored that of many general music classrooms, for it began with games to interest and entice the students, then moved to body percussion, unpitched percussion, vocal, and instrumental experiences. Lukas was concerted in his sequence so that the amount of risk-taking was carefully and gradually increased over the semester. The emphasis on the extrinsic production of improvisation through body percussion and unpitched percussion offered both motivation and success to the students. Thus, success seemed to breed motivation for further learning. When the vocal improvisations began, they were first comical, again motivating students to participate. At the point the vocal improvisations moved to the dramatic, the students were motivated to create something unusual and different (Huovinen et al., 2010), demonstrating confidence in their skills. As Lukas implemented activities with the piano and other instruments, there was more hesitancy, but his consistency in accepting students' improvisations served to entice them. They were excellent risk-takers because he emphasized that he did not come to class with preconceived pieces or tonalities or styles; rather, they occurred in the moment.

The particular progression of activities ranged from simple to complex, comical to serious, very short duration to 20-minute creations. He exhibited a sequence that moved from general 
activities that were common to everyone and needing relatively little explanation to personal and specific activities that often emphasized emotion and expression. While his sequence of teaching appeared carefree, it was, I believe, highly structured, carefully paced, and based on daily results in order to create progress on subsequent days.

\section{Pedagogy}

Scaffolding was abundant, serving to underpin learning, and was identifiable as Lukas moved from the familiar to the unfamiliar without the students seeming to notice. He appeared to exhibit a delicate balance of having complete control of the environment, yet giving the students freedom and acceptance. When he felt they were ready for a change, he utilized different venues seemingly to influence their creations.

Consistently, Lukas emphasized that improvisation was communication (Covington, 1997), so the focus of the course was to teach the students to freely communicate through a variety of experiences and with a variety of musical media. He demonstrated pedagogical skills to produce positive results (Wright \& Kanellopoulos, 2010), those that could be replicated in the public school setting. Lukas was creative and imaginative in his approach, convincing in his arguments, flexibly structured in his teaching (Berliner, 1987; Burnard, 2011), and consistent in his communication about the students' development of skills for teaching. Perhaps the most salient feature of his work was that he consistently created a classroom in which participation and learning were central to the course, both of which could be anticipated; yet, he utilized such a variety of activities and media, that learning appeared to be new and unique for each class.

\section{Implications}

There are several implications that might be highlighted for this study. First, while most classrooms typically focus on individual private learning that includes quizzes and tests, Lukas' classroom offered public, visible, participatory learning that served as examples for everyone. The environment was intentionally designed to offer the students freedom of choice, all without rules, and seemed to foster participation and skill acquisition. Second, Lukas demonstrated a balance in teaching that embraced structure, although flexibility was readily apparent. He seemed to improvise in his teaching (Burnard, 2011) to capture interests of the students and was quick to use their comments to initiate activities that reflected their ideas, conversations, and concerns. Flexibility was presented through modeling rather than direct instruction, perhaps as a means of motivating and empowering the students. Third, his instruction consisted of learning experiences that did not appear to be drill; rather, each was new, showing that every experience was integral to those that followed. As a result, both learning sequence and learning activities offered students models that could be replicated in school music classrooms. Thus, I might suggest that a teacher such as Lukas who is passionate about student learning finds interesting and intentional ways to draw the students into activities to forge experience, confidence, and skills, and dispel fear (Riveire, 2006), all of which might be transferred to their future classrooms. He served as a role model for concerted planning, strategic scaffolding, and engaged learning experiences. Furthermore, while Lukas was not formally trained in improvisation (Shuler, 1995), he essentially utilized his musicianship to train himself, obviously recognizing the importance of the 
skill for future teachers rather than merely continuing to teach as he had been taught. Louth (2012) posed the question " is it possible to teach someone to improvise creatively?" (p. 9). Based on the work of this professor and his students, it is obvious that a wealth of learning occurred in the form of risk-taking, learning sequence and content, communication skills, motivational approaches, psychology, and pedagogy.

\section{Suggestions for future research}

As a result of the current study, future research might focus on the students' individual perceptions of the improvisation course. In particular I would like to investigate their mindsets as they began the course as well as their perceptions of growth and development over the semester. Second, it would be beneficial to research practicing teachers' use of improvisation in music classrooms as a result of instruction at the university. Thus, a triad of studies might provide a clearer picture of the impact of the course for entering and current college students as well as for practicing teachers.

\section{Funding}

This project was funded by a Fulbright Scholars Award to Europe/Eurasisa.

\section{References}

Abrahams, F. (2000). National standards for music education and college preservice music teacher education: A new balance. Arts Education Policy Review, 102(1), 27-31.

Alexander, M. L. (2012). Fearless improvisation: A pilot study to analyze string students' confidence, anxiety, and attitude toward learning improvisation. Update: Applications of Research in Music Education, 31(1), 25-31.

Berliner, D. C. (1987). Ways of thinking about students and classrooms by more and less experienced teachers. In Calderhead, J. (Ed.), Exploring teachers' thinking (pp. 60-83). London, UK: Cassell Education.

Bowman, W. D. (1988). Doctoral research in jazz improvisation pedagogy: An overview. Bulletin of the Council for Research in Music Education, 96, 47-76.

Burnard, P. (2011). Creativity, pedagogic partnerships, and the improvisatory space of teaching. In Sawyer, K. (Ed.), Structure and improvisation in creative teaching. Cambridge, UK: Cambridge University Press.

Covington, K. (1997). Improvisation in the aural curriculum: An imperative. College Music Symposium,37, 49-64.

Creswell, J. W. (2009). Qualitative, quantitative, and mixed methods approaches. Thousand Oaks, CA: SAGE.

Della Pietra, C., Campbell, P. S. (1995). An ethnography of improvisation training in a music methods course. Journal of Research in Music Education, 43, 112-126.

Gamso, N. M. (2011). An aural learning project: Assimilating jazz education methods for traditional applied pedagogy. Music Educators Journal, 98(2), 61-67. 
Glesne, C., Peshkin, A. (1992). Becoming qualitative researchers: An introduction. White Plains, NY: Longman.

Griffiths, M., Woolf, F. (2009). The Nottingham apprenticeship model: Schools in partnership with artists and creative practitioners. British Educational Research Journal, 34(4), 557-574.

Huovinen, E., Tenkanen, A., Kuusinen, V. P. (2010). Dramaturgical and music-theoretical approaches to improvisation pedagogy. International Journal of Music Education, 29(1), 82100.

Kratus, J. (1995). A developmental approach to teaching music improvisation. International Journal of Music Education, 26(1), 27-38.

Louth, J. P. (2012). An approach to improvisation pedagogy in post-secondary jazz programmes based on negative dialectics. Music Education Research, 14(1), 9-24.

May, L. F. (2003). Factors and abilities influencing achievement in instrumental jazz improvisation. Journal of Research in Music Education, 51(3), 245-258.

Merriam, S. B. (2001). Qualitative research and case study applications in education. San Francisco, CA: Jossey-Bass.

Monk, A. (2012). The five improvisation "brains": A pedagogical model for jazz improvisation at high school and the undergraduate level. International Journal of Music Education, 30(2), 89-98.

Patton, M. Q. (1990). Qualitative evaluation and research methods (2nd ed.). Newbury Park, CA: SAGE.

Riveire, J. (2006). Using improvisation as a teaching strategy. Music Educators Journal, 92(3), 40-45.

Rubin, H., Rubin, I. (2005). The art of qualitative interviewing. Thousand Oaks, CA: SAGE.

Sawyer, R. K. (Ed.). (2011). Structure and improvisation in creative teaching (pp. 279-298).

Cambridge, UK: Cambridge University Press.

Seddon, F., Biasutti, M. (2010). Strategies students adopted when learning to play an improvised blues in an e-learning environment. Journal of Research in Music Education, 58(2), 147-167.

Shuler, S. C. (1995). The impact of national standards on the preparation, in-service professional development, and assessment of music teachers. Arts Education Policy Review, 96(3), 2-15.

Smith, D. T. (2009). Development and validation of a rating scale for wind jazz improvisation performance. Journal of Research in Music Education, 57(3), 217-235.

Smith, L. M. (1978). An evolving logic of participant observation, educational ethnography and other case studies. In Shulman, L. (Ed.), Review of research in education. Itasca, IL: Peacock.

Stake, R. E. (1995). The art of case study research. Thousand Oaks, CA: SAGE.

Watson, K. E. (2010). Charting future directions for research in jazz pedagogy: Implications of the literature. Music Education Research, 12(4), 383. 
Wehr-Flowers, E. (2006). Differences between male and female students' confidence, anxiety, and attitude toward learning jazz improvisation. Journal of Research in Music Education, 54(4), 337-349.

Wright, R., Kanellopoulos, P. (2010). Informal music learning, improvisation and teacher education. British Journal of Music Education, 27(1), 71-87. 